\title{
Thorax update for the 60th year (October 2005-September 2006)
}

\author{
J A Wedzicha, S L Johnston, D M Mitchell
}

A nother year has passed since our last annual report for Thorax ${ }^{1}$ and, in this important 60th year and diamond jubilee for the journal, we are delighted that Thorax has continued to be so successful. As for the past 2 years, $^{23}$ the impact factor for 2005 , released in June 2006, has now risen from 5.04 in 2004 to 6.15. Thorax has maintained its position as the second highest ranked respiratory journal in terms of impact factor, behind the American Journal of Respiratory and Critical Care Medicine. The impact factor for 2005 reflects the number of citations in 2005 divided by the number of original papers and reviews published in Thorax in 2003 and 2004. Although the value of the impact factor has been much debated, the reality is that many national research assessment exercises require published research papers to be in appropriately highly ranked journals. The rise in the impact factor has led to the large number of high quality articles submitted over the past few years. The latest 2005 impact factors for the main respiratory journals are listed in table 1 .

The number of submissions over the past year was 1477, of which 900 were full original papers. Table 2 shows the geographical spread of the submissions. The time to the first decision on a paper is now at a median of 27 days, which also includes statistical review for all

Table 1 Journal impact factors for 2005: respiratory journals

$\begin{array}{ll}\text { American Journal of Respiratory } & 8.689 \\ \text { and Critical Care Medicine } & \\ \text { Thorax } & 6.150 \\ \text { Chest } & 4.008 \\ \text { American Journal of Respiratory } & 3.988 \\ \text { Cell and Molecular Biology } & \\ \begin{array}{l}\text { European Respiratory Journal } \\ \text { American Journal of Physiology - }\end{array} & 3.947 \\ \text { Lung Cellular and } & 3.939 \\ \text { Molecular Pathology } & \\ \text { Tuberculosis } & 3.899 \\ \text { Journal of Thoracic and } & 3.727 \\ \text { Cardiovascular Surgery } & \\ \text { Journal of Heart and Lung } & 2.992 \\ \text { Transplantation } & \\ \text { Respiratory Medicine } & \end{array}$

potentially acceptable papers. However, the large number of submissions, particularly for original papers, means that our acceptance rate for original research papers now stands at around 12\%, although for case reports and Images in Thorax the acceptance rate is lower. In view of the large number of submissions, we have to reject some papers and a considerable number of case reports without review. We feel that at the initial submission, if a paper definitely cannot make the standard for publication in Thorax, it is in the authors' interest to try another journal without delay. A review of the balance of the journal showed that approximately 45\% of the papers in Thorax are on asthma and COPD, and this proportion has remained steady over the past 3 years. Among the other topics, there are still relatively few submissions of papers on lung cancer, considering the considerable burden of the disease. During the past year we received 95 letters for publication, consisting of both correspondence about previously published papers and also research letters, which are all peer reviewed as for original papers.

We are grateful to all our reviewers who have taken the time to review papers for the journal. ${ }^{4}$ The rigorous standard of peer review has helped to achieve the high quality of papers published in the journal. Table 3 shows the country of origin of reviewers; compared with last year there is a small rise in the number of reviewers from Europe (excluding the UK) and the
USA, with a small fall in the number of UK reviewers. ${ }^{1}$

Over the past year an issue of concern in the journal has been that $33 \%$ of our requests for review have been declined, which presumably reflects increasing pressure of work. We have always encouraged authors to suggest reviewers for their papers, and in October 2005 we published a report on the outcome of papers where authors suggested reviewers compared with those papers where no reviewers were suggested. ${ }^{5}$ The results showed that only $57 \%$ of authors suggested reviewers, and these were more likely to be authors who were English speaking and writing papers on asthma. The suggestion of reviewers by authors seemed to be a surrogate marker of manuscript quality, and reviewers suggested by authors tended to be more favourable to publication than reviewers suggested by editors.

It is the Editor's responsibility to ensure that there is something in the journal each month of interest to all readers, and thus educational features are important in Thorax. Our Lung Alerts, which are short summaries of papers published in general and nonrespiratory journals and serviced by our younger readers, ${ }^{6}$ have continued to be very popular, together with the "Images in Thorax" feature where we publish radiological and pathological images together with a short commentary.

Table 3 Recruited Thorax reviewers by country of origin: 1 October 2005-30 September 2006

\begin{tabular}{lrl}
\hline Country & N & \% \\
\hline UK & 325 & 36.7 \\
Europe (excluding UK) & 218 & 24.6 \\
USA and Canada & 232 & 26.2 \\
Japan & 6 & 0.7 \\
Australasia & 82 & 9.3 \\
Asia & 9 & 1 \\
South America & 3 & 0.34 \\
Africa & 4 & 0.45 \\
Middle East & 7 & 0.8 \\
Total & & \\
\hline
\end{tabular}

Table 2 Geographical spread of submissions: 2001-2006

\begin{tabular}{lrrrrrr}
\hline & $\mathbf{2 0 0 1}$ & $\mathbf{2 0 0 2}$ & $\mathbf{2 0 0 3}$ & $\mathbf{2 0 0 4}$ & $\mathbf{2 0 0 5}$ & $\mathbf{2 0 0 6}$ \\
\hline UK & 323 & 325 & 378 & 398 & 373 & 373 \\
Europe (excluding UK) & 386 & 329 & 437 & 527 & 525 & 514 \\
USA and Canada & 68 & 74 & 126 & 146 & 187 & 183 \\
Japan & 69 & 74 & 99 & 107 & 100 & 77 \\
Australasia & 57 & 45 & 67 & 86 & 75 & 101 \\
Asia & 26 & 41 & 85 & 125 & 165 & 159 \\
South America & 7 & 6 & 21 & 23 & 25 & 21 \\
Africa & 5 & 1 & 6 & 11 & 18 & 9 \\
Middle East & 24 & 21 & 21 & 26 & 35 & 32 \\
\hline & & & & & &
\end{tabular}


The Images series is available free of charge in a dedicated collection on the Thorax website (http://thorax. bmjjournals.com/cgi/collection/images). A report on the British Thoracic Society (BTS) Winter meeting held in London in December 2005 was published early this year. ${ }^{8}$ We also published BTS guidelines on recommendations for assessing risk and for managing Mycobacterium tuberculosis infection and disease in patients due to start anti-TNF- $\alpha$ treatment ${ }^{9}$ and more recently, we published recommendations for the management of cough in adults from the BTS Cough Guideline Group. ${ }^{10}$ Reviews in the journal are either commissioned or submitted as occasional reviews and sent for peer review. This year we have also started a review series on exacerbations of airway diseases, with five reviews already published on exacerbations of COPD, followed by reviews on asthma exacerbations; next year we will complete the series with reviews on exacerbations in cystic fibrosis and bronchiectasis.

There have been a number of changes in the editorial board of the journal this year-we welcome Moira Whyte (UK) as an associate editor and two new associate editors with an interest in epidemiology, Richard Hubbard (UK) and David Mannino (USA). We had our annual meeting of the associate editors in November 2005 at which Fiona Godlee, editor of the British Medical Journal, gave us a useful presentation about issues raised at the Fifth International Congress on Peer Review and Biomedical Publication held in Chicago in September 2005. We then held our usual breakfast meeting of the Thorax
International Advisory Board at the American Thoracic Society in May 2006 which was well attended, and I thank the Advisory Board members for their support and contributions to the lively debate.

In July 2006 we were very sorry to say farewell to Ed Howard who started with us on Thorax in October 2002 as our Editorial Assistant and then was promoted to Development Manager, and with whom many of you had communicated over papers. Ed has now been promoted to a post in the corporate division of BMJ Publishing and we all thank him for his excellent support and organisation of the journal over the past 4 years, for his skill in transferring Thorax to an online system at the start of our editorship, for wise advice and always great enthusiasm for our journal. We all wish him much success in his new post.

We would like to thank Andrea Horgan, the Managing Editor of Thorax, for her support of the journal, Julia Cresswell, our editorial assistant, and Gavin Stewart who has taken over from Ed Howard as Development Editor. Changes are also taking place in the technical editing of the journal which will now be outsourced, and the December issue will be the last one that will be edited by Liz Stockman who has served as Technical Editor of Thorax for very many years, including for previous Editors. We are sorry to lose Liz and we are all very grateful to her for the many years of loyal service to Thorax, for her meticulous and skilful technical editing, ensuring that all the material is of the highest quality and the journal always looks so good. We would also like to thank Sheila Edwards,
John Macfarlane, Howard Hosker, and the BTS for their support of Thorax over the year.

Finally, we wish all our Thorax readers all over the world a very Happy Christmas and a successful and productive New Year in 2007.

Thorax 2006;61:1035-1036.

doi: $10.1136 /$ thx.2006.072710

Authors' affiliations

J A Wedzicha, S L Johnston, D M Mitchell,

Thorax Editorial Office

Correspondence to: Professor J A Wedzicha, Thorax Editorial Office; thorax@bmigroup.com

\section{REFERENCES}

1 Wedzicha JA, Johnston S, Mitchell D. Thorax Annual Report 1 October 2004 to 30 September 2005. Thorax 2005;60:987-8.

2 Wedzicha JA, Johnston SL, Mitchell DM. Journal impact factors for 2003: Thorax increases. Thorax 2004;59:736

3 Wedzicha JA, Johnston SL, Mitchell DM. Journal impact factors for 2003: another rise for Thorax. Thorax 2005:60:712.

4 Wedzicha JA, Johnston SL, Mitchell DM. Thank you to all Thorax reviewers. Thorax 2004;59:6-7.

5 Hurst JR, Howard EC, Wedzicha JA. Reviewer selection: author or editor knows best? Thorax 2005;60:799

6 Wedzicha JA, Bhowmik A, Seemungal T. Call for Lung Alerts. Thorax 2003;58:193.

7 FitzGerald JM, Müller N, Hogg J. Images in Thorax. Thorax 2003;58:915.

8 Wilkinson TMA, Baghai-Ravery R, Perera WR. British Thoracic Society Winter Meeting 2005. Thorax 2006;61:280-3.

9 British Thoracic Society Standards of Care Committee. BTS recommendations for assessing risk and for managing Mycobacterium tuberculosis infection and disease in patients due to start anti-TNF- $\alpha$ treatment. Thorax 2005;60:800-5

10 Morice AH, McGarvey L, Pavord I, on behalf of the British Thoracic Society Cough Guideline Group. Recommendations for the management of cough in adults. Thorax 2006;61(Suppl 1):i1-24.

\section{BTS WINTER MEETING: CELEBRATING 60 YEARS OF THORAX}

A special symposium to mark the $60^{\text {th }}$ anniversary year of Thorax

- Friday 8 December 2006 at 11 am-12noon

- Abbey Room, Westminster Conference Centre

- Chair: Professor Peter Calverley, President BTS

- The Early Years of Thorax: Professor Anthony Seaton (Editor 1977-1982)

- Thorax at 60! Professor Wisia Wedzicha (present Editor)

- Specialist journals in the future: Dr Fiona Godlee (Editor BMJ) 